\title{
Suffix interference in Russian
}

\author{
Lindy Comstock*
}

\begin{abstract}
The phenomenon of "suffix interference" has been used as evidence for a distinction between inflectional and derivational processes (e.g. Pinker \& Prince, 1988; Pinker, 1999; Pinker \& Ullman, 2002). Yet much of the work on affix priming exists in English, a morphologically poor language, and suffix interference appears inconsistently in cross-linguistic data. The greater reliance on morphological complexity in Russian, and its use of an infinitival suffix and aspectual affixes that may bridge the distinction between traditional definitions of inflectional and derivational word forms, call into question how generalizable the original findings on suffix interference may be for morphologically-complex languages. Investigating these questions, this paper provides unexpected findings: suffix interference is absent in Russian, inflectional suffixes reveal significantly more robust priming effects, and the infinitival suffix is best considered a special case of affix priming, failing to pattern with either inflectional or derivational suffixes. Thus, Russian appears to defy the assumption that inflections are "stripped" during morphological parsing; instead, verbal inflections prove the greatest facilitators of morphological priming. A linear mixed effects model indicates these effects cannot be explained by frequency alone.
\end{abstract}

Keywords. morphological priming; inflectional processing; Russian; suffix interference; lexical decision

1. Introduction. Early studies of linguistic processing commonly rely upon English language data, thereby revealing a need to test basic assumptions about the theoretical foundations of the field in languages that differ from English in their formal properties. Given the morphologicallypoor status of English, this concern is particularly relevant for questions of how lexical entries are thought to be formed, and what hierarchical relationships may exist between related lexical entries. These distinctions between inflectional and derivational processes have played an important role in forming our understanding of the relationship between lexical entries within the mental lexicon.

The literature posits three processes of complex word formation that can be differentiated by means of morphological priming: inflectional and derivational morphology, which add affixes to a stem, and word compounding, which combines stems. The original work on affix priming (e.g. Taft \& Forster, 1976; Burani, Salmaso \& Caramazza, 1994) relied heavily on a distinction between derivational and inflectional processes, which were assumed to differ in their ability to form new lexical entries (e.g. Pinker \& Prince, 1988; Pinker, 1999; Pinker \& Ullman, 2002). Addition of an inflectional suffix was assumed not to change the grammatical form of a word or the semantics of the word stem; instead, inflected forms were thought to be calculated based on rules stored within the stem's lexical entry. Obligatory decomposition of the inflected form was thus required to access the lexical entry of the stem, in the absence of an independent lexical entry for the inflected form. In contrast, derivational morphology was assumed to change the grammatical form of the word and to affect its meaning, thereby generating a new lexical entry distinct from the stem (cf. Marslen-Wilson, 2007).

\footnotetext{
*Author: Lindy Comstock, University of California, Los Angeles (lbcomstock@ucla.edu).
} 
Suffix interference provides support for this model of the mental lexicon because the phenomenon is purported to affect only derivational word forms: a word stem with one derivational affix fails to prime the same stem with a different derivational affix (MarlsenWilson et al., 1994; Marslen-Wilson \& Zhou, 1999), whereas a bare stem produces a priming effect for the same stem combined with a derivational affix (Marslen-Wilson et al., 1994). This finding was interpreted to indicate that derivational affixes "block" access to a stem's lexical entry, and that derivational processes create separate lexical entries. However, the experimental paradigms by which inflectional and derivational suffixes are investigated in the literature largely differ. Most often, morphological priming studies test inflectional morphology as a bare verb stem paired with a past tense inflected form (e.g., Drews \& Zwitserlood, 1995; Forster et al., 1987). Given the assumption that inflectional affixes are "stripped" and devoid of semantic meaning, few current studies investigate the potential priming effect of inflectional suffixes when appended to different stems, in effect failing to test the equivalent of derivational suffix priming or suffix interference in their inflected counterparts.

The priming effect of derivational suffixes independent of a shared stem (e.g., MarslenWilson et al., 1994) was assumed to relate to the ability of derivational suffixes to bear semantic meaning, although the proposition that only certain types of affixes bear semantic content appears non-intuitive for morphologically-complex Slavic languages, in which aspectual affixes may change semantic meaning while retaining the same grammatical category. The application of the English morphological priming literature to Slavic languages is further problematized by a lack of common terms. What is considered a word "stem" in English is quite straightforward: it is the word form with no affixes (e.g., play minus -ing, $-s$, or -ed). However, in Slavic languages, traditional morphological divisions include a root, which may be appended to a verbal stem and multiple affixes (cf. Townsend, 1968). In the case of infinitives, the root is typically followed by a verbal stem and an inflectional affix (e.g., hrom- $a-t$ '). Therefore "stem priming", one of the most productive types of morphological priming in English, possesses no clear equivalent in Russian. If the intermediary categorizations of complex Russian words (e.g., hrom- $a$ minus $-t^{\prime}$ ) can be proven as a psycholinguistic reality, this further complicates the relation of surface form words to their abstract lexical entries.

Although suffix interference has been shown to appear in some, primarily European languages, the finding lacks consistency, even across closely-related language families. The phenomenon has been observed in English (Marslen-Wilson et. al, 1994; Marslen-Wilson, Zhou, \& Ford, 1996; Marslen-Wilson \& Zhou, 1999) and German (Sonnenstuhl, Eisenbeiss, \& Clahsen, 1999). Yet studies in Dutch (Zwitserlood, Bolwiender, \& Drews, 1995; Zwitserlood, Drews, \& Bolwiender, 2002) and French (Meunier, Marslen-Wilson, \& Ford, 2000) have failed to produce suffix interference. The literature on Slavic literatures is sparse, but Reid \& MarslenWilson $(2000,2003)$ claim to have reproduced the effect in Polish. Unfortunately, controversial categorization of the experimental material sheds some doubt on the Polish findings. In particular, Reid \& Marslen-Wilson (2000, 2003) report the most robust facilitation effect for "stem priming", yet utilize infinitives in lieu of a bare stem, despite acknowledging that the former clearly possess an infinitival suffix.

In the literature on Russian morphological priming, aspectual prefixes rather than inflectional or derivational suffixes are the focus of three of the four available morphological priming experiments, although these studies stand in contradiction to one another. The first cites morphological facilitation regardless of semantic transparency (Kazanina et al., 2008), which 
could be argued to render irrelevant the traditional distinction between inflected and derived forms based the criteria of differentiating semantic content of the affixes. In a subsequent study, priming effects were determined to be independent of target frequency (Kazanina, 2011), a finding contested by a more recent study of aspectual prefixes in verbs and deverbal nouns (Slioussar \& Chuprina, 2016). Recent trends in the literature favor attribution of priming effects to a calculated frequency of surface form, stem, and affix (e.g., Baayen, Hendrix, \& Ramscar, 2013), however, although worthy of additional study, this finding has as-of-yet found little support from Russian data.

The fourth study on Russian morphological priming is the most relevant to the current investigation, and gains support from parallel findings in Serbian and Czech experiments. These three studies all illustrate differences between verbal infections and other affix types, but in ways not anticipated by the English literature. VanWagenen \& Pertsova (2014) noted the lack of inflectional studies, and discovered robust inflectional priming effects, but only for verbal rather than nominal inflections. In Czech, Smolik (2010) also found more consistent effects for verbal inflections than for nominal ones. Finally, Feldman (1994) obtained priming effects for derivational and inflectional affixes in Serbian, contrary to the predictions for English. Inflectional affixes provided a significantly greater facilitation effect, which was interpreted as evidence of a "more transparent" morphemic structure. The rationale for why this effect obtained and why verbal inflections facilitate more strongly than nominal ones still requires much study, but it is clear Slavic languages preclude a simple division of inflectional and derivational processes.

This paper will begin to address these questions by investigating affix priming and the behavior of derivational, inflectional, and infinitival suffixes in Russian. The primary aim will be to attempt reproduction of the phenomenon of suffix interference found in Polish. The presence or absence of suffix interference will be used to assess what, if any, differences can be found between the three suffix types. A secondary aim consists in establishing effects related to the infinitive as a case of affix priming rather than stem priming. Specifically, infinitival affixes will be investigated to see if they pattern with derivational and inflectional affixes, or if they produce unique results.

\section{Method.}

2.1 PARTICIPANTS. Forty-two Russian university students between the ages of eighteen and twenty-three residing in Saint Petersburg, Moscow, and Magnitogorsk provided informed consent to participate in the study on a voluntary basis. All subjects possessed normal hearing and normal or corrected vision.

2.2 STIMULI. Eight conditions were created in total. Six conditions tested for stem and suffix priming in derivational, inflectional, and infinitival prime-target pairs. The first condition held derivational suffixes constant from prime to target, which differed by stem. The subsequent condition reversed this relation, as implicated in suffix interference: primes and targets shared a stem but possessed different derivational suffixes. The same two conditions were constructed for inflectional suffixes. The infinitival suffix constitutes just one letter, combined with an orthographic sign of palletization. This pairing occurs in numerous nouns in addition to infinitive forms. Therefore, inflectional suffixes were combined with the verbal suffix of four conjugation types (e.g., - $\left.-\hat{a}-t^{\prime},-a-t^{\prime},-e-t^{\prime},-i-t^{\prime}\right)$ to disambiguate the morphological relation between the prime and target. Inflectional suffixes appended to different stems were tested for a priming effect, as 
were infinitives paired with a related deverbal noun. This condition corresponds to what was termed "stem priming" in Reid \& Marslen-Wilson's (2003) experiment claiming suffix interference in Polish. Morphologically related pairs necessarily contain considerable semantic and phonological overlap, and thus both semantic and phonological priming posed possible confounds for the experiment. To address this concern, the final two conditions presented primetarget pairs that bore only a semantic or phonological relation, respectively. Semantic relations between Russian prime-target pairs were established based on the results of a cognitive association experiment (Panchenko et al., 2016; accessed online 1/1/2017).

\begin{tabular}{|c|c|c|c|c|c|}
\hline Condition & Example & $\mathrm{N}$ & $\begin{array}{c}\text { MLF (SD) } \\
\text { Prime }\end{array}$ & $\begin{array}{c}\text { MLF (SD) } \\
\text { Control }\end{array}$ & $\begin{array}{c}\text { MLF (SD) } \\
\text { Target }\end{array}$ \\
\hline $\begin{array}{l}\text { 1. Derivational suffixes, } \\
\text { matched (-tel', -ost', -un, } \\
\text {-n'e, -ovoj, -ebnyj, -ëlyj, } \\
\text {-ënyj) }\end{array}$ & $\begin{array}{c}\text { pravitel'/ }^{\prime} \\
\text { DERŽATEL' }\end{array}$ & 10 & $2(2)$ & $1(1)$ & $1(1)$ \\
\hline $\begin{array}{l}\text { 2. Derivational suffix } \\
\text { interference (-na, -tel', } \\
\text {-'ba, -ec, -n'e, -ka, -ost', } \\
\text {-nie, -nyj, -skij, -ovoj, -lyj) }\end{array}$ & $\begin{array}{c}\text { rodina/ } \\
\text { RODITEL' }\end{array}$ & 10 & $3(3)$ & $1(1)$ & $1(1)$ \\
\hline $\begin{array}{l}\text { 3. Inflectional suffixes, } \\
\text { matched (-ât, -it, -iš', -u, - } \\
\text { im) }\end{array}$ & $\begin{array}{c}\text { šipât/ } \\
\text { ZVENÂT }\end{array}$ & 10 & $2(2)$ & $1(2)$ & $1(2)$ \\
\hline $\begin{array}{l}\text { 4. Inflectional suffix } \\
\text { interference (-ât, -at, - -ût, } \\
\text {-u, -ûu, -it, -et) }\end{array}$ & $\begin{array}{c}\text { brosât/ } \\
\text { BROŠU }\end{array}$ & 10 & $4(6)$ & $1(1)$ & $1(1)$ \\
\hline $\begin{array}{l}\text { 6. Infinitival suffixes, } \\
\text { matched (t'; conjugation } \\
\text { types: -ât', -at', -et', -it') }\end{array}$ & $\begin{array}{c}\text { penât'/ } \\
\text { RONÂT }\end{array}$ & 10 & $2(2)$ & $1(2)$ & $1(2)$ \\
\hline $\begin{array}{l}\text { 5. Infinitival suffix/ } \\
\text { Inflectional suffix (t'; } \\
\text { conjugations: -ât', -at', -et', } \\
\text {-it', -nut'; -tel', -ka, -na, -ost', } \\
\text {-ovoj, -sikik, -učij, -sivyj, -nyj) }\end{array}$ & $\begin{array}{c}\text { hromat'l } \\
\text { HROMOTA }\end{array}$ & 10 & $7(7)$ & $1(2)$ & $1(2)$ \\
\hline 7. Semantic overlap & $\begin{array}{l}\text { krepost'l } \\
\text { BAŠNÂA }\end{array}$ & 10 & $28(12)$ & $12(7)$ & $12(7)$ \\
\hline 8. Phonological overlap & $\begin{array}{l}\text { robkij/ } \\
\text { SKOBKI }\end{array}$ & 10 & $8(10)$ & $2(2)$ & $2(2)$ \\
\hline
\end{tabular}

Suffixes marked in bold. MLF per million words.

Table 1: Stimuli items

Ten related prime-target pairs were created for each of the eight conditions and matched with control pairs containing the same word type as the experimental target and an unrelated word prime. Experimental and control pairs were matched for syllable length, number of letters, mean lemma frequency, and standard deviation (Lyashevskaya \& Sharov, 2009; accessed online 
1/1/2017). Examples of each condition are presented in Table 1. Given substantial orthographic overlap between prime-target pairs, primes appeared in lowercase font, and targets in capital letters. To render yes responses $50 \%$ of the total and to reduce the proportion of related words to $365 \%, 65$ related real/non-real, 44 unrelated real word, and 139 unrelated real/non-word pairs were added (see Rastle et al., 2004).

2.3 PRocedure. Audio stimuli were recorded by a female Russian native speaker. Targets appeared in white font on a grey background, at a delay of $500 \mathrm{~ms} \mathrm{sec}$ after the primes/controls, displayed with the program Psychopy (Peirce, 2007, 2009). Two lists of four blocks each were created, with half of the participants receiving each list. Each prime-target pair appeared once for each participant, and the presentation order of experimental items and fillers was pseudorandomized. A practice session of 30 pairs initiated the experiment, and 10 dummy items preceded each block. Participants were instructed to respond quickly, yet accurately to each target, using their dominant hand to press a key on the computer keyboard marked with a green dot to indicate the word was real, and their non-dominant hand to press a key marked with a red dot to indicate a non-word. RTs were measured from the onset of target presentation.

3. Results. The results of eleven subjects were discarded from the final analysis: three with average RTs over one second, and eight with an error rate of greater than $15 \%$. Participants reported difficulty in accurately completing the lexical decision task, indicating a potential chance of false positives or incorrect rejections. To mitigate dual risks of inaccurate responses and overzealous pruning of the data, error responses were retained in the analysis, but only for participants who performed with greater than $85 \%$ accuracy. Accuracy results were similar across conditions. As an alternative to unilaterally excluding all error responses, which could contain false rejections, participants were instead asked to identify unknown words from a complete list of the targets. Two target items identified by greater than $15 \%$ of participants as unknown were removed from the analysis.

Selecting a method of removing outliers is a subject of debate in the literature. RTs that exceeded 1.5 seconds or were less than $100 \mathrm{~ms}$ were removed as an initial step. Following Ratcliff's (1993) recommendations, exclusion of two standard deviations from the mean, calculated per participant for the RTs remaining after the initial removal of outliers, was deemed the most suitable exclusion criteria for an experiment with an anticipated small effect size and an effect located in the body of the distribution. Less than $10 \%$ of RTs were discarded. Average response times and priming effects are summarized in Table 2.

3.1 MAGNITUDE OF PRIMING EFFECTS. T-tests revealed a significant priming effect for all but three conditions: Inflectional suffixes, Semantic overlap, and Phonological overlap. Given no significant evidence of semantic and phonological priming, these conditions were excluded from further analysis. The greatest priming effect was found for suffixes: Inflectional suffixes, followed by derivational suffixes. The interference conditions for inflectional and derivational word forms, which tested access to a common lexical entry for prime and target, also proved to generate a priming effect for both affixes; this effect was greater for inflectional suffixes, but the difference was not significant. The difference in magnitude of the priming effect for matched suffix conditions versus the interference conditions did reach significance.

The infinitival suffix provided a unique pattern of results that did not fully conform to either of the other suffix types. Pairs formed from the same stem with an infinitival suffix as the prime and a derivational suffix as the target produced a priming effect nearly identical in magnitude to 
that of the derivational suffix interference condition. This would suggest that infinitival suffixes approximate derivational ones, except for the lack of significance difference between the facilitation in both interference conditions. Furthermore, when infinitival suffixes were paired without a common stem, RTs were impaired. This finding is especially striking, as the condition was the only one that failed to produce any facilitation.

\begin{tabular}{|c|c|c|c|c|c|}
\hline Condition & Example & $\begin{array}{c}\text { Prime } \\
\text { RT }\end{array}$ & $\begin{array}{c}\text { Control } \\
\text { RT }\end{array}$ & $\begin{array}{l}\text { Priming } \\
\text { effect }\end{array}$ & $\mathrm{p}$ value \\
\hline 1. Derivational suffixes & $\begin{array}{c}\text { pravitel'/ }^{\prime} \\
\text { DERŽATEL' }\end{array}$ & 645 & 688 & $43 *$ & $\mathrm{p}<0.001$ \\
\hline $\begin{array}{l}\text { 2. Derivational suffix } \\
\text { interference }\end{array}$ & $\begin{array}{c}\text { rodina/ } \\
\text { RODITEL' }\end{array}$ & 625 & 642 & $17 *$ & $\mathrm{p}=0.023$ \\
\hline 3. Inflectional suffixes & $\begin{array}{c}\text { šipât/ } \\
\text { ZVENÂT }\end{array}$ & 629 & 682 & $53 *$ & $\mathrm{p}<0.001$ \\
\hline 4. Inflectional suffix interference & $\begin{array}{c}\text { brosât/ } \\
\text { BROŠU }\end{array}$ & 637 & 658 & $21 *$ & $\mathrm{p}=0.0077$ \\
\hline 5. Infinitival suffixes & $\begin{array}{c}\text { penât'/ } \\
\text { RONÂT' }^{\prime}\end{array}$ & 651 & 638 & -13 & $\mathrm{p}=0.091$ \\
\hline 6. Infinitival/derivational suffixes & $\begin{array}{c}\text { hromat'/ } \\
\text { HROMOTA }\end{array}$ & 646 & 662 & $16^{*}$ & $\mathrm{p}=0.027$ \\
\hline 7. Semantic overlap & $\begin{array}{l}\text { krepost'/ } \\
\text { BAŠNÂA }\end{array}$ & 619 & 632 & 13 & $\mathrm{p}=0.073$ \\
\hline 8. Phonological overlap & $\begin{array}{l}\text { robkij/ } \\
\text { SKOBKI }\end{array}$ & 652 & 657 & 5 & $\mathrm{p}=0.49$ \\
\hline
\end{tabular}

Table 2: Reaction times and priming effects

3.2 GENERAL STATISTICAL ANALYSIS. Response times were analyzed with linear mixed effects models using the package lme4/lmerTest (Bates et al. 2014) in R (R Core Team 2014). The best fit model included the factors listed in Table 3. Each model was evaluated relative to its improvement over a model that included only random effects, and over the next best fit model.

\begin{tabular}{|l|c|c|c|c|}
\hline \multicolumn{1}{|c|}{ Main Effect } & $b$ & SE & $\mathrm{t}(30)$ & $\mathrm{p}$ \\
\hline Condition & $-6.276 \mathrm{e}-03$ & $6.448 \mathrm{e}-03$ & -0.973 & $\mathrm{p}<0.001$ \\
\hline Target frequency & $-1.102 \mathrm{e}-04$ & $2.753 \mathrm{e}-05$ & -4.002 & $\mathrm{p}<0.001$ \\
\hline Target letters & $3.406 \mathrm{e}-03$ & $4.570 \mathrm{e}-03$ & 0.745 & $\mathrm{p}<0.001$ \\
\hline Morphological relatedness & $-2.179 \mathrm{e}-02$ & $5.480 \mathrm{e}-03$ & -3.976 & $\mathrm{p}<0.001$ \\
\hline Prime frequency & $-4.222 \mathrm{e}-06$ & $1.698 \mathrm{e}-06$ & -2.486 & $\mathrm{p}<0.001$ \\
\hline Prime letters & $-5.667 \mathrm{e}-03$ & $2.584 \mathrm{e}-03$ & -2.194 & $\mathrm{p}<0.001$ \\
\hline Condition*Target frequency & $1.521 \mathrm{e}-05$ & $3.956 \mathrm{e}-06$ & 3.845 & $\mathrm{p}<0.001$ \\
\hline Condition*Target letters & $3.788 \mathrm{e}-04$ & $8.874 \mathrm{e}-04$ & 0.427 & $\mathrm{p}<0.001$ \\
\hline
\end{tabular}

Table 3: Linear mixed-effects model

The main effect of morphological relatedness reflects faster RTs for morphologically related prime-target pairs over their unrelated controls. A best fit model could not be obtained without a 
main effect of morphological relatedness, indicating that frequency cannot fully explain the effects without taking morphological structure into consideration.

However, target frequency and prime frequency produced main effects and interactions with the main effect of condition. Although experimental and control pairs were matched for MLF, this metric differed across conditions due to unavoidable limitations in the word forms available for each condition. The primes in affix priming conditions ranged from 2 to 7 occurrences per million words, whereas the semantic condition and phonological conditions reached a MLF of 28 and 10 occurrences per million words, respectively. Controls and targets for affix priming remained loccurrence per million words throughout all conditions, rising to 12 and 2 occurrences per million words for the semantic and phonological conditions. These numbers are provided in Table 1.

Upon closer look at the RTs obtained for each condition relative to the MLF, it becomes apparent that no clear pattern arises such to assume that either frequency or length can determine the priming effects. Consistently across all conditions and morphological type of suffix, the RTs fail to correspond strictly to the length or frequency of stimuli items. RTs relative to syllable length and letter number are provided in Table. 4.

\begin{tabular}{|l|c|cc|cc|}
\hline \multicolumn{1}{|c|}{ Condition } & $\begin{array}{c}\text { Prime } \\
\text { RT }\end{array}$ & $\begin{array}{c}\text { Control } \\
\text { RT }\end{array}$ & $\begin{array}{c}\text { Priming } \\
\text { effect }\end{array}$ & Syllables & Letters \\
\hline $\begin{array}{l}\text { 1. Derivational suffixes } \\
\text { 2. Derivational suffix } \\
\text { interference }\end{array}$ & 645 & 688 & $43 *$ & $3-3$ & $8(1)$ \\
\hline 3. Inflectional suffixes & 625 & 642 & $17 *$ & $3-3$ & $8(1)$ \\
\hline 4. Inflectional suffix interference & 637 & 658 & $21 *$ & $2-2$ & $5(1)$ \\
\hline 5. Infinitival suffixes & 651 & 638 & -13 & $2-2$ & $6(1)$ \\
6. Infinitival/derivational suffixes & 646 & 662 & $16 *$ & $2-3$ & $7(1)$ \\
\hline 7. Semantic overlap & 619 & 632 & 13 & $2-2$ & $6(1)$ \\
\hline 8. Phonological overlap & 652 & 657 & 5 & $3-2$ & $7(1)$ \\
\hline
\end{tabular}

Table 4: RTs by syllables and letters

The semantic overlap condition illustrates a significantly faster average RT, yet other the responses garnered by other conditions are not significantly different from RTs found in other conditions. In numerous cases, longer words nonetheless generated faster response times to primes, suggesting that other considerations should take precedence. The semantic condition is also the category that produced the highest MLF for stimuli items: 28 versus 1-7 occurrences per million words for the affix priming conditions. Yet frequency distinctions in other conditions appear minimal and are best evaluated by means of a statistical model. 
3.2 STATISTICAL ANALYSIS BY CONDITION. In order to better interpret the interactions reported in the general model, separate linear mixed effects models were considered for each condition. In particular, given variance in the frequency and length of stimuli items between conditions, it was important to investigate if effects of frequency and length obtained in the general model would emerge as a significant factor in all, or only a subset of the individual conditions.

The derivational suffix condition exhibited a significant main effect of morphological relatedness $(b=0.04283, \mathrm{SE}=0.01671, \mathrm{t}(19)=2.563$. Surprisingly, despite the difference in greatest differences in world length in this condition, neither frequency nor the number of letters generated a significant effect.

The derivational suffix interference condition relies upon a morphological similarity in the stem, rather than in the suffix. This condition generated significant main effects of prime frequency $(b=1.221 \mathrm{e}-05, \mathrm{SE}=1.726 \mathrm{e}-02, \mathrm{t}(19)=0.63$, target frequency $(b=-2.019 \mathrm{e}-04, \mathrm{SE}=$ 5.002e-05, $\mathrm{t}(19)=-4.04)$, morphological relatedness $(b=-7.418 \mathrm{e}-04, \mathrm{SE}=2.119 \mathrm{e}-02, \mathrm{t}(19)=$ -0.04 , and interactions between morphological relatedness and target frequency $(b=1.230 \mathrm{e}-04$, $\mathrm{SE}=6.476 \mathrm{e}-05, \mathrm{t}(19)=1.90)$, and morphological relatedness and prime frequency $(b=$ $-6.256 \mathrm{e}-05, \mathrm{SE}=2.620 \mathrm{e}-05, \mathrm{t}(19)=-2.39)$. In this condition the addition of the factors of target letters neared but failed to reach significance.

The inflectional suffix condition revealed a significant main effect of morphological relatedness $(b=-0.05296, \mathrm{SE}=0.01268, \mathrm{t}(19)=-4.18)$.

The inflectional suffix interference condition exhibited significant main effects of Morphological relatedness $(b=-2.304 \mathrm{e}-02, \mathrm{SE}=9.445 \mathrm{e}-03, \mathrm{t}(19)=-2.44)$ and Target frequency $(b=-4.820 \mathrm{e}-05, \mathrm{SE}=2.296 \mathrm{e}-05, \mathrm{t}(19)=-2.10)$.

The infinitival suffix condition is the only condition to fail to reveal a main effect of morphological relatedness. However, the condition does exhibit a significant main effect of target frequency $(b=-1.229 \mathrm{e}-04, \mathrm{SE}=4.627 \mathrm{e}-05, \mathrm{t}(19)=-2.66)$.

The infinitival/derivational suffix condition, erroneously referred to as "stem" priming in the Polish literature, displayed significant main effects of morphological relatedness $(b=-2.477 \mathrm{e}$ $02, \mathrm{SE}=9.484 \mathrm{e}-03, \mathrm{t}(19)=-2.612)$, target frequency $(b=-7.751 \mathrm{e}-05, \mathrm{SE}=2.102 \mathrm{e}-05, \mathrm{t}(19)=-$ 3.686), prime frequency $(b=-8.369 \mathrm{e}-07, \mathrm{SE}=2.853 \mathrm{e}-06, \mathrm{t}(19)=-0.293)$, target letters $(b=$ $3.235 \mathrm{e}-03, \mathrm{SE}=4.308 \mathrm{e}-03, \mathrm{t}(19)=0.751)$, prime letters $(b=1.685 \mathrm{e}-02, \mathrm{SE}=5.924 \mathrm{e}-03, \mathrm{t}(19)=$ $2.844)$, and an interaction between morphological relatedness and target frequency $(b=4.882 \mathrm{e}-$ $05, \mathrm{SE}=2.922 \mathrm{e}-05, \mathrm{t}(19)=1.671)$.

4. Discussion. It is quite striking that the two conditions that generated the largest magnitude of priming effect were also the two conditions where morphological relatedness played the most significant role: the derivational suffix and inflectional suffix conditions. Both derivational conditions necessitated a mix of long and short word forms, yet frequency and length only became significant factors in the suffix interference condition. Thus, both the stems and suffixes in Russian remain important in morphological processing of word forms, but a processing advantage for derivational suffixes over stems emerges.

This same distinction and advantage found between stem and suffix conditions are mirrored in inflectional morphology. The greatest facilitation is shown to come from morphological relatedness in non-interference conditions, without extra facilitation from frequency or length 
effects. Despite the shorter word forms utilized in stimuli items for the inflectional suffix interference condition, this condition appears to be affected by the frequency of the stimuli items, just as the derivational suffix interference condition relied upon a number of effects to produce a relatively smaller magnitude of facilitation.

Infinitival suffixes remain the most mysterious. If the two infinitival conditions are taken separately, the Infinitival/derivational suffix condition appears to pattern in a manner similar to the derivational suffix interference condition, both generating a similar magnitude of priming and relying upon multiple effects for that facilitation. However, the infinitival suffix fails to generate any facilitation when not appended to a related stem. Infinitival suffixes are small, constituting only two characters (three with the verbal stem), yet suffixes even smaller (one character) facilitated priming in the inflectional suffix condition. Thus, an alternative explanation must be found. Infinitival suffixes could be argued to be "stripped" during the processing of these word forms, except a motivation for their unique treatment still needs to be obtained. Future studies may wish to attempt morphological priming with stimuli items that contain no verbal suffixes. In general, the complicating factor of intermediary suffixes persist throughout the experiment, as derivational forms frequently possess more than one suffix. While this study indicates that intermediary forms do not impede morphological priming, disambiguating the role of intermediary forms and surface forms and their relative status in the mental lexicon remains an important topic to be investigated.

5. Summary. These findings confirm that suffix interference is not universal in Slavic languages. Interference effects failed to surface for either derivational or inflectional affixes. To the contrary, all suffix types facilitated reaction times, with the exception of infinitival suffixes, even with the addition of a verbal suffix to the infinitival suffix. Yet infinitives paired with derivational word forms did produce a priming effect, illustrating that this morphological category cannot be considered to fully correspond to either derivational or inflectional affixes. Inflectional suffixes appeared generated the strongest facilitation, an effect that appears to be independent of frequency, especially in the non-interference conditions. Most surprisingly, minimal and extremely productive suffixes such as the inflectional suffix still generated a priming effect, even when stimuli item pairs did not share a morphologically-related stem. These findings problematize the traditional conception of the mental lexicon, at the same time as they challenge current frequency-based approaches which disregard morphology. In morphologicallycomplex languages, such as Russian, morphology remains an important tool in linguistic processing.

\section{References}

Baayen, R. Harald, Peter Hendrix \& Michael Ramscar. 2013. Sidestepping the combinatorial explosion: An explanation of n-gram frequency effects based on naive discriminative learning. Language and Speech 56(3). 329-347. https://doi.org/10.1177/002383091348 4896.

Burani, Cristina, Dario Salmaso \& Alfonso Caramazza. 1984. Morphological structure and lexical access. Visible Language 18(4). 342. https://search.proquest.com/docview/ 1297965553 ? accountid=14512.

Drews, Etta \& Zwitserlood, Pienie. 1995. Morphological and orthographic similarity in visual word recognition. Journal of Experimental Psychology: Human Perception and Performance 21(5). 1098. https://doi.org/10.1080/01690960444000160. 
Feldman, Laurie. B. 1994. Beyond orthography and phonology: Differences between inflections and derivations. Journal of Memory and Language 33(4). 442-470. https:// doi.org/10.1006/ jmla.1994.1021.

Forster, Kenneth I., Davis, Chris, Schoknecht, Colin, \& Carter, R. 1987. Masked priming with graphemically related forms: Repetition or partial activation?. The quarterly journal of experimental psychology. 39(2). 211-251. https://doi.org/10.1080/14640748708401785.

Kazanina, Nina. 2011. Decomposition of prefixed words in Russian. Journal of Experimental Psychology: Learning, Memory, and Cognition 37(6). 1371-1390. http://doi.org/ 10.1037/a0024335.

Kazanina, Nina, Galina Dukova-Zheleva, Dana Geber, Vikor Kharlamov \& Keren Tonciulescu. 2008. Decomposition into multiple morphemes during lexical access: A masked priming study of Russian nouns. Language and Cognitive Processes 23(6). 800-823. https://doi.org/10.1080/01690960701799635.

Lyashevskaya, Olga N., \& Sergey A Sharov. 2009. Chastotnyj slovar'sovremennogo russkogo iazyka (na materialakh Natsionalnogo korpusa russkogo iazyka) [Frequency dictionary of modern Russian based on the Russian National Corpus]. Moscow: Azbukovnik. http:// ruscorpora.ru/1 grams.top.html.

Marslen-Wilson, William. 2007. Processes in language comprehension. The Oxford Handbook Psycholinguistics 11(175). 495-524.

Marslen-Wilson, William., Tyler, Lorraine. K., Waksler, Rachelle., \& Older, Lianne. 1994. Morphology and meaning in the English mental lexicon. Psychological review, 101(1). 3-33.

Marslen-Wilson, William \& Xiaolin Zhou. 1999. Abstractness, allomorphy, and lexical architecture. Language and Cognitive Processes 14(4). 321-352. https://doi.org/10.1080/ 016909699386257.

Marslen-Wilson, William, Mike Ford, Lianne Olde , \& Xiaolin Zhou, . 1996. The combinatorial lexicon: Priming derivational affixes. In Proceedings of the eighteenth annual conference of the Cognitive Science Society. 223. University of California, San Diego. Psychology Press.

Meunier, Fanny, William Marslen-Wilson \& Mike Ford. 2000. Suffixed word lexical representations in French. In ISCA tutorial and research workshop (ITRW) on spoken word access processes. 31-34. http://www.isca-speech.org/archive_open/ swap/swap _031.html.

Panchenko, Alexander, Dmitry Ustalov, Nikolay Arefyev, Denis Paperno, Natalia Konstantinova, Natalia Loukachevitch \& Chris Biemann. 2016. Human and machine judgements for Russian semantic relatedness. In International conference on analysis of images, social networks and texts. 221-235. Cham: Springer. http://russe. nlpub.org/downloads/.

Pastizzo, Matthew J. \& Laurie B Feldman. 2002. Discrepancies between orthographic and unrelated baselines in masked priming undermine a decompositional account of morphological facilitation. Journal of Experimental Psychology: Learning, Memory, and Cognition 28(1). 244. https://doi.org/10.1037//0278-7393.28.1.244.

Peirce, Jonathan W. 2007. PsychoPy-Psychophysics software in Python. Journal of neuroscience methods. 162(1-2). 8-13. https://doi.org/10.1016/j.jneumeth.2006.11.017.

Peirce, Jonathan W. 2009. Generating stimuli for neuroscience using PsychoPy. Frontiers in Neuroinformatics. 2. 10. https://doi.org/10.3389/neuro.11.010.2008. 
Pinker, Steven. 1999. Words and rules: The ingredients of language. New York: Harper Collins.

Pinker, Steven, \& Alan Prince. 1988. On language and connectionism: Analysis of a parallel distributed processing model of language acquisition. Cognition 28(1). 73-193. http://doi.org/ 10.1016/0010-0277(88)90032-7.

Pinker, Steven \& Michael T. Ullman. 2002. The past and future of the past tense. Trends in Cognitive Sciences 6(11). 456-463. https://dx.doi.org/10.1016/S1364-6613(02)01990-3.

Rastle, Kathleen, Matthew H. Davis \& Boris New. 2004. The broth in my brother's brothel: Morpho-orthographic segmentation in visual word recognition. Psychonomic Bulletin \& Review 11(6). 1090-1098. https://doi.org/10.3758/BF03196742.

Ratcliff, Rodger. 1993. Methods for dealing with reaction time outliers. Psychological Bulletin. 114(3). 510. https://doi.org/10.1037/0033-2909.114.3.510.

Reid, Agnieszka, \& William Marslen-Wilson. 2000. Organizing principles in lexical representation: Evidence from Polish. In Proceedings of the twenty-second annual conference of the Cognitive Science Society. 387-392. Psychology Press. https:// escholarship.org/uc/item/04c982zn.

Reid, Agnieszka. A. \& William Marslen-Wilson. 2003. Lexical representation of morphologically complex words: Evidence from Polish. In R. Harald Baayen \& Robert Schreuder (eds.), Morphological structure in language processing. 287-337. Berlin: Mouton de Gruyter.

Slioussar, Natalia, \& Chuprina, Anastasia. 2016. How derivational links affect lexical access: evidence from Russian verbs and nouns. Italian Journal of Linguistics 28(1). 115-136.

Smolik, Filip. 2010. Inflectional suffix priming in Czech verbs and nouns. In Proceedings of the 32nd annual meeting of the Cognitive Science Society. 1668-1672. https:/cloudfront.escholarship.org/dist/prd/content/qt66n6h6s3/qt66n6h6s3.pdf.

Sonnenstuhl, Ingrid, Sonja Eisenbeiss \& Harald Clahsen. 1999. Morphological priming in the German mental lexicon. Cognition 72(3). 203-236. https://dx.doi.org/10.1016/S00100277(99)00033-5.

Taft, Marcus, \& Forster, Kenneth. I. 1976. Lexical storage and retrieval of polymorphemic and polysyllabic words. Journal of verbal learning and verbal behavior. 15(6). 607-620. https://dx.doi.org/10.1016/0022-5371(76)90054-2.

Townsend, Charles. 1968. Russian word formation. New York: McGraw-Hill.

VanWagenen, Sarah \& Katya Pertsova. 2014. Asymmetries in priming of verbal and nominal inflectional affixes in Russian. UCLA Working Papers in Linguistics 18. 49-59. http:// phonetics.linguistics.ucla.edu/wpl/issues/wpl18/papers/svwpertsova.pdf.

Zwitserlood, Pienie, Agnes Bolwiender \& Etta Drews. 1995. Die lexikalische Aktivierung morphologisch komplexer Verben. In, Onur Güntürkün, Rainer Guski, C. Walter and A. Wollschlager (eds.), Experimentelle Psychologie. Regensburg: S. Roderer Verlag.

Zwitserlood, Pienie, Etta Drews \& Agnes Bolwiender. 2002. Separate contributions of morphology, form, and meaning? Evidence from Dutch. Manuscript, University of Münster. 